\title{
Discontinuation of Statin Treatment in Relation to Chronic Diseases and Laboratory Findings
}

\author{
Leo Niskanen ${ }^{1,2}$, Janne Suvisaari ${ }^{3}$, Jaana Suvisaari ${ }^{4}$, Anna But ${ }^{5}$, Jari Haukka ${ }^{4,5 *}$ \\ ${ }^{1}$ Finnish Medicines Agency Fimea, Helsinki, Finland; ${ }^{2}$ School of Medicine, Faculty of Health Sciences, University of Eastern Fin- \\ land, Kuopio, Finland; ${ }^{3}$ HUSLAB Laboratories, Department of Clinical Chemistry, Helsinki University Central Hospital, Helsinki, \\ Finland; ${ }^{4}$ National Institute for Health and Welfare (THL), Helsinki, Finland; ${ }^{5}$ Hjelt Institute, University of Helsinki, Helsinki, \\ Finland. \\ Email: leo.niskanen@fimea.fi; janne.suvisaari@hus.fi; jaana.suvisaari@thl.fi; anna.but@helsinki.fi; jari.haukka@helsinki.fi
}

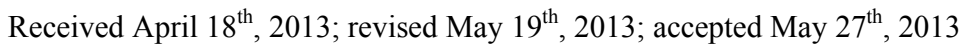

Copyright (C) 2013 Leo Niskanen et al. This is an open access article distributed under the Creative Commons Attribution License, which permits unrestricted use, distribution, and reproduction in any medium, provided the original work is properly cited.

\begin{abstract}
Purpose: The aim was to study discontinuation of statin treatment, especially with respect to clinical characteristics and adverse effect measured by clinical laboratory tests indicating muscle damage (plasma creatine kinase, CK) and liver AEs (plasma alanine aminotransferase, ALAT). Methods: The initial study population included 60,488 individuals who had purchased first time statin prescription in Helsinki-Uusimaa region between 01-01-2007 and 31-12-2009. The follow-up started when first statin prescription was purchased and ended 31-12-2009 or death, which ever occurred first. From this population 54,172 individuals were defined to eligible to study population of this study. Clinical laboratory measurements were obtained from Helsinki-Uusimaa University Hospital (HUSLAB) that which provides the laboratory tests for the Helsinki-Uusimaa region serving about a population of 1.5 million. Results: In this fairly large real-life study the occurrence of ALAT-AE and mild CK-elevations after initiation of first statin treatments were relatively low. Increasing age and the presence of co-morbidities increased the risk of these AEs. Further, the ALAT-AEs implied increased risk of discontinuation of treatment. Diabetic patients discontinued treatment more often than nondiabetics, whereas the presence of other chronic conditions implied higher persistence of statin treatment. Conclusions: It is essential that those who would benefit from statin therapy actually are treated and by far in most patients treatment seems to be safe and well tolerated. For those who cannot tolerate statins new therapeutic options are needed.
\end{abstract}

Keywords: Statins; Adverse Effects; Discontinuation

\section{Introduction}

The 3-hydroxy-3-methylglutaryl-coenzyme A (HMG$\mathrm{CoA}$ ) reductase inhibitor class of drugs (statins) reduce plasma cholesterol by more than $20 \%$ [1]. Statins also increase survival and reduce the incidence of adverse cardiovascular events in both secondary and primary coronary heart disease (CHD) prevention trials. These drugs as a class effect have favorable safety profile [2] and benefits are seen in many groups [3,4]. However, despite this favorable safety profile statins are not devoid of adverse effects (AEs). The most common AEs are those related to muscle and liver enzymes. In controlled clinical trials these have been quite rare occurrences [2], but recent cohort reports [5] and clinical experience suggest

${ }^{*}$ Corresponding author. that these muscle and liver AEs associated with statin use are quite common with estimates ranging from $10 \%$ $20 \%$ [6]. The statin discontinuation rates are surprisingly high, about $30 \%$ within the first year of initiation of therapy [7-10]. One somewhat hitherto neglected and underestimated aspect is that the discontinuation of statins might increase the risk of adverse outcomes in acute coronary syndromes or stroke [11-13]. It has been even suggested that the withdrawal of statins may be worse than never taking statins in relation to outcomes [14].

The aim of this study is to study discontinuation of statin treatment, especially with respect to clinical characteristics and adverse effect measured by clinical laboratory tests indicating muscle damage (plasma creatinekinase, CK) and liver AEs (plasma alanine aminotransferase, ALAT, also called glutamic pyruvic transami- 
nase).

\section{Methods}

\subsection{Study Population and Data Sources}

The initial study population included 60,488 individuals new users of statins who had purchased first time statin prescription in Helsinki-Uusimaa region between 01-012007 and 31-12-2009. These data were obtained from Finnish Social Insurance Institution (SII). New user was defined to be without statin prescription in previous year. Data of purchased statin prescriptions for study periods included the following information: subject ID, date of purchase, amount purchased (in defined daily dose, DDD) [15], and ATC (Anatomical Therapeutic Chemical) for drug. Information of dates and causes of death was obtained from Statistics Finland [16]. The follow-up started when first statin prescription was purchased and ended 31-12-2009 or death, which ever occurred first. From this population 54,172 individuals were defined to eligible to this study, because their follow-up time was longer than $99 \mathrm{~d}$.

Clinical laboratory measurements were obtained from Helsinki-Uusimaa University Hospital (HUSLAB) that provides the laboratory tests for the Helsinki-Uusimaa region serving about a population of 1.5 million Individual level data were linked using unique social security number (SSN), and after linking the original SSN was replaced by a study person identification number (ID). Thus, the study group utilized only anonymous data with Study ID. Study protocol was reviewed by ethical committee of Hjelt Institute of Medical Faculty, University of Helsinki.

\subsection{Statin Discontinuation}

Continuous statin usage sequences were constructed by assuming usage of one DDD per day, and allowing maximum 90 days gap between prescriptions. Thus, e.g. prescription with 30 DDD was assumed to last for 120 days. If there was no new prescription before that, discontinuation of treatment was assumed. Because start of follow-up was defined as the day of the first statin prescription there was certain interval with no discontinuation that was defined by gap (90 d) and smallest prescription (9 DDD). Thus only this "immortal" period (99 d) in respect with discontinuation was not taken into account in analysis, and all censoring during this period were omitted from analysis. Discontinuation was used as outcome variable.

\subsection{Definition of an Adverse Event and Other Explanatory Variables}

One of the aims of the study is to investigate the association between observed adverse events (AE) and discon- tinuation of statin treatment. The occurrence of an AE was determined using clinical laboratory measurements from HUSLAB Laboratories. AE is defined to take place after start of follow-up (purchase of the first statin prescription) and before discontinuation of statin treatment or censoring event (31-12-2009 or death).

Two adverse events used in this study were defined as follows:

- For ALAT a value twice the baseline level (measured within one year before start of follow-up) or, if a baseline level was not available, twice the upper limit of the reference range (70 U/1 for males and $45 \mathrm{U} / 1$ for females) [17].

- $\mathrm{CK}$ : For CK a value twice the upper limit of the reference range (400 U/1 for males under 50 years and $210 \mathrm{U} / 1$ for females).

Age, sex, and type of first statin purchased were used as background variables. In addition, chronic disease indicators provided by SII special reimbursement register [18] were used. The following diseases were considered: diabetes mellitus, chronic heart failure, chronic hypertension, chronic CHD, familial hypercholesterolemia, and dyslipidemia associated with chronic CHD.

\subsection{Statistical Methods}

The association between $\mathrm{AE}$ and discontinuation of statin treatment was modeled using Cox's proportional hazards model and using AE indicator as time-dependent variable that takes value zero in the start of follow-up. Only the first AE occurring for each individual was taken into account. Background variables such as age, sex, first statin, and chronic disease indicators were included inthe models. We applied also marginal structural models (MSM) approach in order to get grasp on selection bias in respect to AE [19]. Inverse probability treatment weights were calculated in respect with $\mathrm{AE}$ and used in Cox's proportional hazards model. Weights were constructed using above mentioned background variables. The association between three levels AE (no, ALAT, CK) and background variables was modeled with multinomial regression. All analyses were carried out using $\mathrm{R}$ dataanalysis language [20].

\section{Results}

The mean age of the study population was $57.2\left(1^{\text {st }}\right.$ quartile $\left.49.7,3^{\text {rd }} 65.2\right)$ years for men and $62.1(54.8,69.8)$ years for women, respectively. Men were significantly younger (t-test, $\mathrm{p}<0.0001)$. The basic characteristics of the study population in relation to the occurrence of $\mathrm{AE}$ are shown in Table 1. The frequencies of ALAT elevation were below $5 \%$ on average and CK-elevations less than 1\% (Table 1). The differences between different statins seem to be rather small. 
Table 1. Basic characteristics of study population. (ALAT-AE = plasma alanine aminotransferase adverse effect; $\mathrm{CK}-\mathrm{AE}=$ plasma creatine kinase, CK adverse effect).

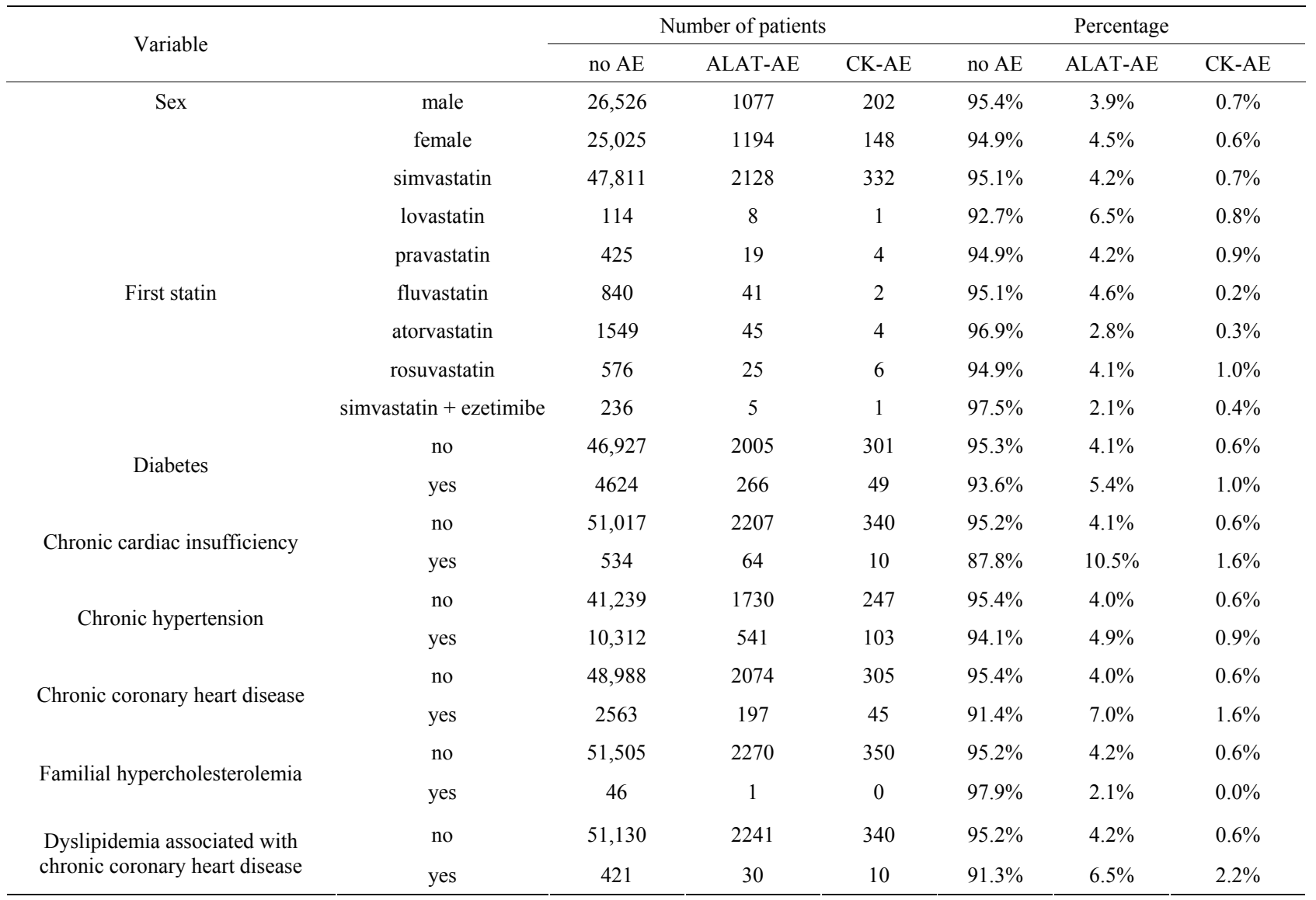

The impact of age, sex and chronic diseases in relation to the occurrence of AEs by multinomial regression are shown in Table 1. Increasing age implied higher risk of AEs so that for one year increase in age the risk of ALAT-AE increased by $1 \%$ and that of CK-AE 5\% (Table 2). In women the ALAT-AE was more common than in men, but CK-AE was more frequent in men. The presence of diabetes increased the risk of ALAT-AE, but the risk of CK-AE was not statistically significant. Likewise, the presence of other chronic conditions increased the risk of AEs and this was statistically significant for those with chronic cardiac failure (ALAT-AE), arterial hypertension (CK-AE), chronic CHD (both AEs) and dyslipidemia associated with CHD (CK-AE).

The mean follow-up time was 1.4 years, and $28 \%$ of statin users discontinued treatment with an average rate of $21 \%$ per year (Table 3). ALAT-AE was associated with an increased risk of discontinuation (hazard ratio, HR $1.16,95 \%$ CI 1.06 - 1.27), but for p CK there was no association (Table 3). Discontinuation was slightly higher for females $(1.11,1.07-1.15)$. The diabetes diagnosis was associated with higher discontinuation rate compared to those without diabetes, but other chronic diseases were associated with lower frequency of discontinuation. E.g. individuals with chronic CHD had 28\% lower (HR 0.72, $0.66-0.79$ ) discontinuation rate than individuals without this condition.

In general results from univariate, multivariate, and marginal structural models were quite similar. Largest difference for dyslipidemia associated with CHDs, where univariate model showed strong inverse association (HR $0.56,0.45-0.70)$ to discontinuation but MSM had no significant effect.

\section{Discussion}

In this fairly large real-life study the occurrence of ALAT-AE and mild CK-elevations after initiation of first statin treatments were relatively low. Increasing age and the presence of co-morbidities increased the risk of these AEs. Further, the ALAT-AEs implied increased risk of discontinuation of treatment. Diabetic patients discontinued treatment more often than non-diabetics, whereas the presence of other chronic conditions implied higher persistence of statin treatment.

Some general limitations must be kept in mind when evaluating the results from any observational study that 
Table 2. Odds ratios and 95\% CI for predicting ALAT-AE (plasma alanine aminotransferase adverse effect) and CK-AE (plasma creatine kinase, CK adverse effect) using multinomial regression (compared to no adverse event).

\begin{tabular}{|c|c|c|c|c|c|c|}
\hline \multirow{3}{*}{$\begin{array}{l}\text { Explanatory variable } \\
\text { Age (years) }\end{array}$} & \multicolumn{3}{|c|}{ P.ALAT } & \multicolumn{3}{|c|}{ P.CK } \\
\hline & \multirow{2}{*}{$\frac{\mathrm{OR}}{1.01}$} & \multicolumn{2}{|c|}{$(95 \% \mathrm{CI})$} & \multirow{2}{*}{$\frac{\mathrm{OR}}{1.05}$} & \multicolumn{2}{|c|}{$(95 \% \mathrm{CI})$} \\
\hline & & 1.01 & 1.02 & & 1.04 & 1.06 \\
\hline Sex (female vs male) & 1.13 & 1.04 & 1.23 & 0.65 & 0.52 & 0.81 \\
\hline Diabetes (yes vs no) & 1.25 & 1.09 & 1.43 & 1.35 & 0.99 & 1.84 \\
\hline Chronic heart failure (yes vs no) & 1.91 & 1.47 & 2.5 & 1.44 & 0.78 & 2.68 \\
\hline Chronic hypertension (yes vs no) & 1.10 & 0.99 & 1.22 & 1.3 & 1.03 & 1.65 \\
\hline Chronic coronary heart disease (yes vs no) & 1.50 & 1.26 & 1.77 & 1.45 & 1.01 & 2.10 \\
\hline Familial hypercholesterolemia (yes vs no) & 0.76 & 0.1 & 5.55 & 0.00 & 0.00 & 0.00 \\
\hline Dyslipidemia associated with chronic coronary artery disease (yes vs no) & 1.07 & 0.72 & 1.58 & 2.05 & 1.01 & 4.18 \\
\hline
\end{tabular}

is based on record linkage. First, the actual usage of prescribed statin could not be verified with certainty, although it is quite likely that most purchased drugs were consumed. Second, it is very probable that not all adverse events during follow-up were recorded, because our information of them was based on sporadic laboratory measurements and some patients may have had their laboratory tests carried out outside the HUSLAB, e.g. in some private laboratories or in some patients the laboratory follow-up after statin initiation may not have been very systematic. We assume that those who experience side-effects within the first year of treatment are usually monitored by liver and muscle enzyme tests. Certainly it is possible that the probability of having these measurements could depend on many background factors, and thus may be tell more about probability to be tested than real probability to have $\mathrm{AE}$. In any scenario, these $\mathrm{AE}$ frequencies most likely underestimate somewhat their true occurrence. On the other hand, if the discontinuation had been due to lack of conviction to prescribed therapy or lack of the clinical response, the biochemical safety tests are less likely to be performed.

Nevertheless, the increased ALAT-AE occurred in about five percent of those whom statin therapy. The increase of ALAT is commonly asymptomatic and transient phenomenon occurring in the first 12 weeks of therapy [17]. This biochemical finding is asymptomatic and not correlated with histopathological changes and therefore does not represent the true liver injury [17]. There are no uniformly accepted definitions of clinical relevance of liver test abnormalities. The frequency of ALAT elevations across multiple studies performed with different types of statins generally does not exceed three percent and in controlled clinical trials the incidence of ALAT-AEs with statins has not been very different from their incidence with placebo [17] (erase text!). However, the ALAT-AE seems to be linked with the dose of statin and not the LDL-reduction achieved [17]. Thus the discontinuation of statins due to ALAT elevation most likely reflects physician's fears of hepatotoxicity. Based on aforementioned it may be that many of these discontinuations could have been avoided with careful followup. There was a female predominance in the occurrence of ALAT-AE in this study. Possibly in women liver enzyme abnormalities generate relatively more anxiety than in men - to the patient and the physician. It is thus conceivable that female patients were also more likely to have ALAT measured.

The most commonly reported AEs of statins are muscle symptoms ranging from muscle pain, fatigue and weakness up to rhabdomyolysis [21]. In randomized clinical trials there has been no excess of muscle problems, but placebo-controlled trials have shown 2.5-fold increased risk of myositis defined by 10 -fold elevation of CK [22]. The occurrence of myalgia is common complaint in statin-users [21] and can occur without CKelevations [23]. In our study even mild elevations of CK were not very frequent and this is in line with the current concept that the occurrence of myositis with significant CK elevations is not a common problem. These CK-AEs did not contribute to the cessation of therapy and thus the clinical significance of this CK-AE is somewhat obscure. However, increasing age and the presence of co-morbidities increased the likelihood of both ALAT- and CK-AEs and thus with increasing age and co-morbidities more alertness for the clinically significant risks are required in patients treated with statins.

The persistence of the described statin therapy during the first 1.4-year was evidently higher in secondary than in primary prevention and ALAT-AEs contributed to the lowered persistence. Type 2 diabetic patients without clinical CVD have a very high risk of cardiovascular events [24] and statin therapy has been shown to reduce this risk [4]. Statin therapy is generally recommended for this group in several national and international treatment guidelines [25]. The poor persistence in diabetic patients may be due to the "glucocentric" approach to this disease by the patients and clinicians alike and thus less emphasis 
Table 3. (a) Discontinuation of statin treatment. Result from univariate Cox's proportional hazards model; (b) Discontinuation of statin treatment. Result from multivariate Cox's proportional hazards model, and marginal structural model.

(a)

\begin{tabular}{|c|c|c|c|c|c|c|c|}
\hline \multicolumn{2}{|l|}{ Variable } & \multirow{3}{*}{$\begin{array}{c}\text { P-years } \\
73,426\end{array}$} & \multirow{3}{*}{$\begin{array}{l}\text { events } \\
15,027\end{array}$} & \multirow{3}{*}{$\begin{array}{l}\text { rate } \\
0.20\end{array}$} & \multicolumn{3}{|c|}{ Univariate model } \\
\hline & & & & & HR & & \\
\hline \multirow[t]{3}{*}{ Adverse effect } & no & & & & 1.00 & 1.00 & 1.00 \\
\hline & ALAT-AE & 2040 & 500 & 0.25 & 1.14 & 1.05 & 1.25 \\
\hline & CK-AE & 348 & 73 & 0.21 & 0.98 & 0.78 & 1.25 \\
\hline \multirow[t]{2}{*}{ Sex } & male & 39,576 & 7695 & 0.19 & 1.00 & 1.00 & 1.00 \\
\hline & female & 36,238 & 7905 & 0.22 & 1.11 & 1.08 & 1.15 \\
\hline \multirow[t]{7}{*}{ First statin } & simvastatin & 69,668 & 14,677 & 0.21 & 1.00 & 1.00 & 1.00 \\
\hline & lovastatin & 203 & 42 & 0.21 & 1.02 & 0.74 & 1.40 \\
\hline & pravastatin & 734 & 122 & 0.17 & 0.81 & 0.67 & 0.97 \\
\hline & fluvastatin & 1668 & 222 & 0.13 & 0.65 & 0.57 & 0.75 \\
\hline & atorvastatin & 1918 & 316 & 0.16 & 0.80 & 0.71 & 0.89 \\
\hline & rosuvastatin & 1168 & 143 & 0.12 & 0.61 & 0.52 & 0.73 \\
\hline & simvastatin + ezetimibe & 456 & 78 & 0.17 & 0.84 & 0.67 & 1.05 \\
\hline \multirow[t]{2}{*}{ Diabetes } & no & 68,772 & 14,062 & 0.20 & 1.00 & 1.00 & 1.00 \\
\hline & yes & 7042 & 1538 & 0.22 & 1.07 & 1.02 & 1.13 \\
\hline \multirow[t]{2}{*}{ Chronic heart failure } & no & 74,857 & 15,448 & 0.21 & 1.00 & 1.00 & 1.00 \\
\hline & yes & 957 & 152 & 0.16 & 0.76 & 0.64 & 0.90 \\
\hline \multirow[t]{2}{*}{ Chronic hypertension } & no & 59,875 & 12,404 & 0.21 & 1.00 & 1.00 & 1.00 \\
\hline & yes & 15,939 & 3196 & 0.20 & 0.97 & 0.94 & 1.01 \\
\hline \multirow{2}{*}{$\begin{array}{l}\text { Chronic coronary } \\
\text { heart disease }\end{array}$} & no & 71,339 & 14,970 & 0.21 & 1.00 & 1.00 & 1.00 \\
\hline & yes & 4475 & 630 & 0.14 & 0.67 & 0.62 & 0.73 \\
\hline \multirow[t]{2}{*}{$\begin{array}{l}\text { Familial } \\
\text { hypercholesterolemia }\end{array}$} & no & 75,739 & 15,589 & 0.21 & 1.00 & 1.00 & 1.00 \\
\hline & yes & 75 & 11 & 0.15 & 0.73 & 0.38 & 1.41 \\
\hline \multirow{2}{*}{$\begin{array}{l}\text { Dyslipidemia associated } \\
\text { with chronic coronary } \\
\text { artery disease }\end{array}$} & no & 74,995 & 15,507 & 0.21 & 1.00 & 1.00 & 1.00 \\
\hline & yes & 819 & 93 & 0.11 & 0.56 & 0.45 & 0.70 \\
\hline
\end{tabular}

(b)

\begin{tabular}{|c|c|c|c|c|c|c|c|}
\hline \multirow[t]{2}{*}{ Variable } & & \multicolumn{3}{|c|}{ Basic Cox's model } & \multicolumn{3}{|c|}{ MSM model } \\
\hline & & \multirow[t]{2}{*}{ HR } & \multicolumn{2}{|c|}{$95 \% \mathrm{CI}$} & HR & \multicolumn{2}{|c|}{$95 \% \mathrm{CI}$} \\
\hline Adverse effect & no & & (reference) & & & (reference) & \\
\hline & ALAT-AE & 1.16 & 1.06 & 1.27 & 1.16 & 1.06 & 1.26 \\
\hline & CK-AE & 1.02 & 0.81 & 1.30 & 1.02 & 0.81 & 1.30 \\
\hline Sex & male & & (reference) & & & (reference) & \\
\hline First statin & $\begin{array}{c}\text { female } \\
\text { simvastatin }\end{array}$ & 1.11 & $\begin{array}{c}1.07 \\
\text { (reference) }\end{array}$ & 1.15 & 1.11 & $\begin{array}{l}1.07 \\
\text { (reference) }\end{array}$ & 1.15 \\
\hline & lovastatin & 1.01 & 0.73 & 1.39 & 1.01 & 0.73 & 1.39 \\
\hline & pravastatin & 0.81 & 0.68 & 0.97 & 0.81 & 0.68 & 0.97 \\
\hline & fluvastatin & 0.65 & 0.57 & 0.74 & 0.65 & 0.57 & 0.74 \\
\hline & atorvastatin & 0.82 & 0.73 & 0.91 & 0.82 & 0.73 & 0.91 \\
\hline & rosuvastatin & 0.63 & 0.53 & 0.74 & 0.63 & 0.53 & 0.74 \\
\hline & simvastatin + ezetimibe & 0.84 & 0.68 & 1.05 & 0.84 & 0.68 & 1.05 \\
\hline Diabetes & no & & (reference) & & & (reference) & \\
\hline & yes & 1.10 & 1.04 & 1.17 & 1.10 & 1.04 & 1.17 \\
\hline Chronic heart failure & no & & (reference) & & & (reference) & \\
\hline Chronic coronary heart disease & $\begin{array}{l}\text { no } \\
\text { yes } \\
\text { no }\end{array}$ & 0.98 & $\begin{array}{c}0.94 \\
\text { (reference) }\end{array}$ & 1.02 & 0.98 & $\begin{array}{l}0.94 \\
\text { (reference) }\end{array}$ & 1.02 \\
\hline Familial hypercholesterolemia & $\begin{array}{l}\text { yes } \\
\text { no }\end{array}$ & 0.72 & $\begin{array}{c}0.66 \\
\text { (reference) }\end{array}$ & 0.79 & 0.72 & $\begin{array}{c}0.66 \\
\text { (reference) }\end{array}$ & 0.79 \\
\hline & yes & 0.83 & 0.43 & 1.59 & 0.84 & 0.43 & 1.61 \\
\hline $\begin{array}{l}\text { Dyslipidemia associated with } \\
\text { chronic coronary artery disease }\end{array}$ & no & & (reference) & & & (reference) & \\
\hline & yes & 0.81 & 0.64 & 1.03 & 0.82 & 0.65 & 1.03 \\
\hline
\end{tabular}


on the treatment of dyslipidemia.

To conclude, in first-time statin users the frequency of liver and muscle enzyme elevations are rather low, but liver enzyme abnormalities reduce the adherence to therapy. The persistence with statin therapy is higher in those with evidence of vascular disease and rather low in diabetic patients. For the prevention of cardiovascular events it is essential that those who would benefit from statin therapy actually are treated and by far in most patients treatment seems to be safe and well tolerated. For those who cannot tolerate statins new therapeutic options are needed.

\section{Acknowledgements}

We are grateful to Finnish Heart Foundation (Sydänsäätiö) for the grant and to HUSLAB for the collaborative work.

Dr. Haukka has been in research collaboration with Janssen-Cilag and Eli Lilly and has been a member of the expert advisory group for Astellas. Dr. Niskanen has performed research collaboration and received lecture or expert opinion fees from Astra-Zeneca, Bayer, BristolMyers Squibb, Ipsen, Janssen Cilag, GlaxoSmithKline, Merck, Eli Lilly, Novartis, Novo Nordisk, Orion Corporation, Roche, Pfizer, and Sanofi-Aventis. Dr. Jaana Suvisaari has served as a consultant to Janssen-Cilag and has received lecture fees from Astra Zeneca.

\section{REFERENCES}

[1] C. Baigent, A. Keech, P. M. Kearney, L. Blackwell, G. Buck, C. Pollicino, et al., "Efficacy and Safety of Cholesterol-Lowering Treatment: Prospective Meta-Analysis of Data from 90,056 Participants in 14 Randomised Trials of Statins," Lancet, Vol. 366, No. 9493, 2005, pp. 12671278. doi:10.1016/S0140-6736(05)67394-1

[2] A. Kashani, C. O. Phillips, J. M. Foody, Y. Wang, S. Mangalmurti, D. T. Ko, et al., "Risks Associated with Statin Therapy a Systematic Overview of Randomized Clinical Trials," Circulation, Vol. 114, No. 25, 2006, pp. 2788-2797. doi:10.1161/CIRCULATIONAHA.106.624890

[3] "MRC/BHF Heart Protection Study of Cholesterol-Lowering with Simvastatin in 5963 People with Diabetes: A Randomised Placebo-Controlled Trial," The Lancet, Vol. 361, No. 9374, 2003, pp. 2005-2016. doi:10.1016/S0140-6736(03)13636-7

[4] P. M. Kearney, L. Blackwell, R. Collins, A. Keech, J. Simes, R. Peto, et al., "Efficacy of Cholesterol-Lowering Therapy in 18,686 People with Diabetes in 14 Randomised Trials of Statins: A Meta-Analysis," Lancet, Vol. 371, No. 9607, 2008, pp. 117-125. doi:10.1016/S0140-6736(08)60104-X

[5] J. Hippisley-Cox and C. Coupland, "Unintended Effects of Statins in Men and Women in England and Wales: Population Based Cohort Study Using the Qresearch Da- tabase," BMJ, Vol. 340, No. 7759, 2010, p. c2197.

[6] D. M. Cutler and W. Everett, "Thinking outside the Pillbox-Medication Adherence as a Priority for Health Care Reform," New England Journal of Medicine, Vol. 362, No. 17, 2010, pp. 1553-1555. doi:10.1056/NEJMp1002305

[7] S. J. Kamal-Bahl, T. Burke, D. Watson and C. Wentworth, "Discontinuation of Lipid Modifying Drugs among Commercially Insured United States Patients in Recent Clinical Practice," The American Journal of Cardiology, Vol. 99, No. 4, 2007, pp. 530-534. doi:10.1016/j.amjcard.2006.08.063

[8] A. Helin-Salmivaara, P. Lavikainen, M. J. Korhonen, H. Halava, S. Y. T. Junnila, R. Kettunen, et al., "Long-Term Persistence with Statin Therapy: A Nationwide Register Study in Finland," Clinical Therapeutics, Vol. 30, 2008, pp. 2228-2240. doi:10.1016/j.clinthera.2008.12.003

[9] C. A. Jackevicius, M. Mamdani and J. V. Tu, "Adherence with Statin Therapy in Elderly Patients with and without Acute Coronary Syndromes," JAMA, Vol. 288, No. 4, 2002, pp. 462-467. doi:10.1001/jama.288.4.462

[10] B. McGinnis, K. L. Olson, D. Magid, E. Bayliss, E. J. Korner, D. W. Brand, et al., "Factors Related to Adherence to Statin Therapy," The Annals of Pharmacotherapy, Vol. 41, No. 11, 2007, pp. 1805-1811. doi:10.1345/aph.1K209

[11] M. Jasińska-Stroschein, J. Owczarek, I. Wejman and D. Orszulak-Michalak, "Novel Mechanistic and Clinical Implications Concerning the Safety of Statin Discontinuation," Pharmacological Reports, Vol. 63, No. 4, 2011, pp. 867-879.

[12] M. Endres and U. Laufs, "Discontinuation of Statin Treatment in Stroke Patients," Stroke, Vol. 37, No. 10, 2006, pp. 2640-2643. doi:10.1161/01.STR.0000240690.69406.28

[13] C. Heeschen, C. W. Hamm, U. Laufs, S. Snapinn, M. Böhm and H. D. White, "Withdrawal of Statins Increases Event Rates in Patients with Acute Coronary Syndromes," Circulation, Vol. 105, No. 12, 2002, pp. 14461452. doi:10.1161/01.CIR.0000012530.68333.C8

[14] S. S. Daskalopoulou, J. A. C. Delaney, K. B. Filion, J. M. Brophy, N. E. Mayo and S. Suissa, "Discontinuation of Statin Therapy Following an Acute Myocardial Infarction: A Population-Based Study," European Heart Journal, Vol. 29, No. 17, 2008, pp. 2083-2091. doi:10.1093/eurheartj/ehn346

[15] "WHO Collaborating Centre for Drug Statistics Methodology," 2008. http://www.whocc.no/

[16] R. Lahti and A. Penttilä, "The Validity of Death Certificates: Routine Validation of Death Certification and Its Effects on Mortality Statistics," Forensic Science International, Vol. 115, No. 1-2, 2001, pp. 15-32. doi:10.1016/S0379-0738(00)00300-5

[17] R. M. Calderon, L. X. Cubeddu, R. B. Goldberg and E. R. Schiff, "Statins in the Treatment of Dyslipidemia in the Presence of Elevated Liver Aminotransferase Levels: A Therapeutic Dilemma," Mayo Clinic Proceedings, Vol. 85 , No. 4, 2010, pp. 349-356. doi: $10.4065 / \mathrm{mcp} .2009 .0365$ 
[18] "Overview of Benefit Programmes 2007," Social Insurance Institution, Finland, 2007.

[19] S. R. Cole and M. A. Hernan, "Constructing Inverse Probability Weights for Marginal Structural Models," American Journal of Epidemiology, Vol. 168, No. 6, 2008, pp. 656-664.

doi:10.1093/aje/kwn164

[20] R Development Core Team, "R: A Language and Environment for Statistical Computing," 2011 http://www.R-project.org/

[21] B. A. Golomb and M. A. Evans, "Statin Adverse Effects: A Review of the Literature and Evidence for a Mitochondrial Mechanism," American Journal of Cardiovascular Drugs, Vol. 8, No. 6, 2008, pp. 373-418. doi:10.2165/0129784-200808060-00004

[22] D. L. McClure, R. J. Valuck, M. Glanz and J. E. Hokanson, "Systematic Review and Meta-Analysis of Clinically Relevant Adverse Events from HMG CoA Reductase Inhibitor Trials Worldwide from 1982 to Present," Pharmacoepidemiology and Drug Safety, Vol. 16, No. 2, 2007, pp. 132-143. doi:10.1002/pds. 1341

[23] P. S. Phillips, R. H. Haas, S. Bannykh, S. Hathaway, N. L. Gray, B. J. Kimura, et al., "Statin-Associated Myopathy with Normal Creatine Kinase Levels," Annals of Internal Medicine, Vol. 137, No. 7, 2002, pp. 581-585. doi:10.7326/0003-4819-137-7-200210010-00009

[24] S. M. Haffner, S. Lehto, T. Rönnemaa, K. Pyörälä and M. Laak, "Mortality from Coronary Heart Disease in Subjects with Type 2 Diabetes and in Nondiabetic Subjects with and without Prior Myocardial Infarction," New England Journal of Medicine, Vol. 339, No. 4, 1998, pp. 229234. doi:10.1056/NEJM199807233390404

[25] A. L. Catapano, Z. Reiner, G. De Backer, I. Graham, M.R. Taskinen, O. Wiklund, et al., The Task Force for the Management of Dyslipidaemias of the European Society of Cardiology (ESC) and the European Atherosclerosis Society (EAS), "ESC/EAS Guidelines for the Management of Dyslipidaemias," Atherosclerosis, Vol. 217, No. 1, 2011, pp. 3-46. doi:10.1016/j.atherosclerosis.2011.06.028 